\title{
Principles of Forming a Modern Accounting and Analytical Model of Commercial Organization in Digital Economy
}

\begin{abstract}
N.S. Plaskova ${ }^{1}$, N.A. Prodanova ${ }^{2}$, V.A. Dikikh ${ }^{3}$, V.E. Kerimov ${ }^{4}$, I.P. Kurochkina ${ }^{5}$, E.V. Prokofieva ${ }^{6}$

Abstract:

Purpose: The article presents basic methodological approaches to the creation of a new model of forming and functioning of the accounting and analytical system to meet the information needs of internal and external stakeholders of organizations.

Design/Approach/Methodology: Substantiation of the principles of building a system for accounting and analytical information management that meets current conditions for the business functioning using modern hardware and software.

Findings: The developed model of cascade functioning of organization's information support system optimizes the structure and content of accounting and analytical modules, contributes to the effective implementation of management functions, timely control and rapid response to the impact of negative factors.

Practical implications: The principles of information flow management system constructing formulated in the article contribute to optimization of expenses for organization of accounting and analytical functions, improvement of quality of financial and non-financial reporting, realistic assessment and forecasting of business efficiency.

Originality/Value: The proposed new model for constructing an accounting and analytical information base allows to improve the procedures of collection, processing, storage and disclosure of financial and non-financial information, to create a balanced structure of the database on the basis of cascade digitization of primary and derived data.
\end{abstract}

Keywords: Accounting and analytical support, information base, stakeholders, principles of information and analytical system development, cascade digitization of accounting and analytical data.

JEL codes: $M 21, M 40, G 32$.

Article Type: Research study.

\footnotetext{
${ }^{1}$ Plekhanov Russian University of Economics, Moscow, Russia.

${ }^{2}$ Plekhanov Russian University of Economics, Moscow, Russia, prodanova-00@mail.ru

${ }^{3}$ Moscow City Teacher Training University, Moscow, Russia.

${ }^{4}$ Moscow state University of Humanities and Economics, Moscow, Russia.

${ }^{5}$ P.G Demidov Yaroslavl State University, Yaroslavl, Russia.

${ }^{6}$ State budgetary institution of higher education of the Moscow region "University" Dubna -

Dmitrov Institute of Continuing Education, Dmitrov, Russia.
} 


\section{Introduction}

In recent years, the program documents approved by the government of Russia, dedicated to the innovative transformation of the economy and its sustainable development, has been noted the need to reform the traditional mechanisms of economic activity. In this context, digital economy is considered as a modern basis for development of the management system of socio-economic potential of the country as a whole and business entities, in particular, which requires a fundamentally different management model based on modern digital technologies, technical means and applied scientific developments in the field of information processing. Issues of improvement of accounting and analytical support are of particular relevance for organizations of basic industries in terms of their importance in achieving the government's objectives aimed at lifting the economy in the coming years, the solution of which depends largely on the development and implementation of modern achievements in the field of digitalization of business space at all levels of management.

\section{Literature Review}

One of the conditions for the development and functioning of a modern system of accounting and analytical information at the organization's management level is to optimize the volume and structure of information resources, its balance as a result of initial processing and subsequent transformations in the process of aggregation and detailing to ensure quality for all interested users, avoiding the asymmetric information access of stakeholders (Decree of the Government of the Russian Federation No. 313, 2014; Decree of the Government of the Russian Federation No. 1030, 2017; Order of the Government of the Russian Federation, 2017).

Regarding the level of economic entity management (level of organization), the specification of one of the main development vectors, aimed at creating an effective digital economy should be considered as high-quality information and analytical support of managerial decisions of stakeholders. The content is a balanced cascade digitization of all economic activities, that are accomplished and planned for implementation, through the coding of indicators and operations. This reflects the dynamics of implementation management functions, including the normalization, planning, forecasting, accounting, reporting, analysis and operational regulation procedures based on scientific principles, models and economic and mathematical methods and algorithms, the use of which eliminates the development of subjectivity in assessing the quality of management and optimize the costs of database management.

Compliance with the condition of balance of accounting and economic information assumes, first, its correct understanding. In general, the balance can be characterized as an equilibrium relationship between a set of aspects, the achievement of a goal depends on its observance (DiPiazza and Eccles, 2003). 
Ansoff (1980) defines the balance from the point of view of the company's development as "the ratio of combinations of strategic elements where the success of the company will be optimal in terms of costs, income, time ... balance in the context of the company's strategy is the constant growth and profitability of the company through the best correlation of life cycles of demand and technology". Kaplan and Norton (2005) understand balance as "the balance between financial and non-financial indicators of the company's activity, between internal and external elements of the system, between lagging and leading indicators".

The solution of the global problem of ensuring the sustainable development of the activities of economic entities is developing a clear mechanism for its solution, creation of appropriate interaction algorithms for stakeholders and enterprises, methods and techniques for determining the range of primary issues, ranking priorities of management tasks (Dunets et al., 2019a; 2019b; Goryushkina et al., 2018; Kolupaev et al., 2019; Jafarpour et al., 2019; Rupeika-Apoga and Saksonova, 2018; Solovjova et al., 2018; Rupeika-Apoga et al., 2018). The basis of such a mechanism is business analysis as a system focused on the creation of high-quality information support for the management system based on innovative methods of internal database management, which is formed in the process of interconnected continuous cascade digitization of all accomplished facts of economic activity, as well as planned budget data.

Generalization and development of business analysis practice is currently carried out by a number of organizations, the leading of which is the International Institute of Business Analysis, which has published a sufficient amount of research results in the field of analytical support for sustainable development process management. However, many issues of analytical substantiation of feasibility of implementation of heterogeneous requirements of business stakeholders continue to remain unresolved (Fedulova et al., 2019; Kashirskaya et al., 2019; Saenko et al., 2019; Pavlyshyn et al., 2019).

\section{Methodology}

The proposed methodological approach is to develop a set of innovative methods, tools and mechanisms to improve the complex of interrelated functions of management processes of economic activity of organizations, the information basis of which is the accounting and analytical database of primary data and derived indicators. The use of the principle of connectedness allowed to create a new model of formation and functioning of the accounting and analytical system, which is based on the end-to-end cascade coding and classification of indicators on actual and planned economic operations, which are "linked" with special tools that reflect the practical nature of the mechanisms of interaction of all business management functions. Assignment of individual codes to each balance account and sub-account (with further detailed coding to the required level of the register), element of business processes, object of management, resource and economic operation allowed 
to create a model of a holistic mechanism of economic activity management as a system that allows to reflect online reliable, transparent information in terms of planning, accounting and management accounting and business analysis on the basis of interrelated indicators for system control of income, expenses, complex of resources used, as well as the formation of reliable management quality assessments for operational and strategic management of companies of different organizational structure and hierarchical level (Korableva et al., 2019).

\section{Results}

In current conditions of economic activity, the urgent purpose is to develop a universal methodological approach and a unified methodological platform for the formation of analytical justification of the system of financial and non-financial indicators, as well as their optimal trigger points, compliance with which ensures satisfaction of financial and other expectations of external and internal stakeholders (Frolova et al., 2019; Khormali et al., 2016). The primary requirements of stakeholders related to information support of their management decisions, as in relation to organizations of all spheres of economic activity, are:

- forming a sufficient, objective, accessible and understandable information containing actual and forecasted parameters of the company;

- comparing expected parameters with their actual values, identifying gaps and business problems related to them;

- analyzing the causes (factors) of the identified problems and the search for ways to solve them;

- developing a balanced system of performance indicators for the organization, intended for its directors and stakeholders, in order to ensure sustainable development;

- $\quad$ selection of specific projects aimed at solving identified problems;

- assessment of total costs for the implementation of sustainable development projects, determination of the volume and structure of sources of financing;

- regular assessment of the effectiveness and financial stability of the company using integrated cascade information about its activities throughout the implementation of projects;

- analytical support for monitoring the balance of cash flows associated with the implementation of these projects, ensuring the solvency of the operating and investment activities of the organization.

The task of improving existing methods and techniques of retrospective economic analysis is also important. The solution of this problem becomes possible if the innovative company reliably reflects in its financial statements the used complex of resources, the costs of its maintenance and restoration, financial results and a liquid cash position. Researches on the organization of accounting procedures and the formation of financial and non-financial corporate reporting show that the 
predominant number of enterprises reflect the cost characteristics of assets, capital, income, expenses and liabilities not quite correctly, which is due to a number of reasons of an objective and subjective nature.

The variability of subjective reflection of various objects in accounting, noncompliance with the rule of prevalence of the fact of a business transaction over its form (documentation), and sometimes intentional distortion of income and expenses in order to minimize tax costs, lead to the fact that even the financial statements that have passed the audit examination do not reflect the real financial and economic situation of the organization, does not allow to objectively assess the impact of external and internal factors on the current and future performance of business (Isaev, 2018; Ivanova et al., 2019; Paptsov et al., 2019; Voronkova et al., 2019)

A significant difficulty in analyzing the effectiveness of organizations is the justification of adequate evaluation characteristics and their optimal parameters, taking into account the specific conditions of business functioning (industry affiliation, legal form, scale, etc.), and the return on invested capital cannot always be measured by the profit parameter, especially since the period of full payback of such investment costs sometimes stretches for decades.

Assessment of business performance should not be limited only to financial indicators. Of relevance in this case are local economic criteria specific to certain stages of the company's life cycle, such as indicators of labour productivity, positive dynamics of the volume and quality of products, its fundamentally new consumer properties. It also needs to include indicators of the use of material resources, the balance of their needs, the costs of creating a high-quality information environment, and the return of labor resources (the cost of labor and social contributions, the value of the social package, the cost of training and advanced training, the quality of labour organization, etc.). We should not lose sight of the significant amount of costs for introducing innovations in the field of information and analytical support for a business management system. From this perspective, the interpretation of the effectiveness of managing the entire set of economic activity resources associated with the traditional assessment of profitability does not meet the principles of objectivity and reliability.

One of the most important features of the methodological approaches used to assess the effectiveness of the organization is the target nature and targeting of the information to various users, since the set of assessment criteria and the level of generalization of analytical indicators can vary significantly depending on who evaluates it and for what purposes: state governing bodies, investors, management and owners of organizations, etc. Given these circumstances, it is necessary to create a holistic accounting and analytical system for assessing the quality level of financial and economic management of the analyzed object. 
Information and analytical support of the company's internal management should be understood as an ordered combination of financial and non-financial information used in the process of control, analysis and planning for the operational and strategic management of financial and economic activities. To solve local management problems, information should be properly selected, structured, generalized, and relevant to a specific problem. Basic information on financial and economic activities for management purposes is generated according to the data of primary documents and business transaction registers, operational, accounting, managerial, production accounting, internal reporting, financial, non-financial reporting, tax accounting and reporting, statistical accounting and reporting (Radina, 2015).

In addition to the information generated in the course of economic activity, external information (macroeconomic and social indicators, regulatory and methodological documents regulating the activities of organizations, current indicators of financial markets, banking and insurance, as well as information on counterparties, etc.) should be used to solve a number of management tasks.

The proposed methodological approach to the formation of the organizational structure of the collection and processing of the database for the purposes of comprehensive economic analysis of the innovative company is based on the system integration of all management functions, including planning and forecasting, accounting, statistical, managerial, operational accounting and preparation of a complex of different forms of retrospective, prospective and operational reporting, analysis of financial and economic activities, control, management evaluation and operational regulation. Generated analytical information within the framework of the proposed information-analytical system is based on a fundamentally new principle of "connectedness", the need for the use of which was noted by the Norwalk Agreement (Norwalk, Connecticut, USA) dated September 18, 2002 of the International Accounting Standards Board - IASB) - by the developer of International Financial Reporting Standards (IFRS, International Financial Reporting Standards - IFRS, International Accounting Standards - IAS) and the Financial Accounting Standards Board - FASB ) - by the developer of the Generally Accepted Accounting Principles of the United States of America (US GAAP). The Agreement provides for the creation of a project to improve financial statements and the development of a fundamentally new reporting format.

The purpose of the agreement was to create a perfect new, built on the principle of coherence of financial statements, containing clear and comparable data on companies of different types and scales of activity: "Financial statements should be presented in such a way that the cross-cutting relationship of indicators between the reports was transparent" (Yakutin, 2016).

The General idea of creating a fundamentally new model of information base management (hereinafter MIBM), built on uniform functional codes of indicators (products, works, services, costs, elements, etc.) and economic actual and planned 
operations, is based on a vision of a holistic management system of the company's activities, taking into account all functional components.

To streamline the data arrays, multifunctional and multilevel codes are developed and relationships between indicators are established, which allows creating a single format for the structure of the general plan of economic activity and integrated reporting. In turn, such a structured multilevel cascaded information system makes it possible to combine analytical indicators to obtain a single integrated assessment of business management, capable of disaggregation to provide the necessary targeted reporting, evaluation and forecast information for managers at various levels. In addition, the use of special software allows you to generate high-quality system information on individual components and objects of control in online mode.

In the process of creating MIBM, the following basic methodological approaches were used:

1. Coding (digitization) of indicators-balance sheet accounts, which are divided by economic essence into three parts: income, expenses and sources in order to create fundamentally new information structures - Unified Digital Plan (UDP) and a Digital Management Balance (DMB). Each balance sheet account corresponds to a certain indicator, which is assigned a code consisting of certain functional elements that reflect the information necessary for the formation of financial, management reporting and analysis of financial and economic activities.

2. Coding (digitization) of business transactions. In existing information systems, transaction registration data in the accounting system in the relevant correspondence of accounts is accumulated in accounting registers. At the same time, the economic and legal content of the business transaction is not reflected simultaneously as a consequence of making of certain managerial decisions, that is, there is no reflection of the relationship between the legal form and the economic content of business transactions and their effectiveness for objective assessment by various users of information. In the developed MIBM to reflect the content of information on the performed accounting transaction, the name of the business transaction is "divided" into two components, each of which is assigned a code associated with the indicator code. Thus, the disclosure of the dual economic and legal meaning in all business transactions was achieved. It is important to note that this approach, based on the principle of connectivity, allowed to link and systematize the economic and legal nature of the real and nominal financial and economic flows.

3. Coding (digitization) of accounting transactions. For the purposes of accounting in the MIBM, the codes of indicators and business transactions are interconnected by a special cascade coding procedure: all possible accounting entries are encoded and linked to the initial documents. This technology provides control aimed at preventing the primary incorrect registration of business transactions. At the same time, the entry of primary records into the accounting system is carried out automatically according to the codes of transactions, accounts, indicators with the 
necessary level of primary detail that are pre-recorded using special software. This allows you to automatically accumulate and convert data to the DMB and standard accounting registers.

4. Building the structure of the Unified Digital Plan (UDP). A balanced UDP has been developed for all indicators of the organization's economic activity, which combines and coordinates various types of plans for certain aspects of the activity, based on the implementation of the principle of connectedness. Planned indicators are calculated pursuant to the associated established standards in accordance with the design, technological and technological documentation, the plan of production and sale of products (works, services).

5. Proactive System Control. This approach provides the possibility of proactive automated control aimed at preventing excess of actual costs over normative planning, volume and price indicators for the entire range of inventory items and services, as well as payments to suppliers and other contractors. Based on the coding of all production and economic indicators, through the main internal audit mechanism, operations with violation in the sphere of procurement and supply activities, as well as any other illegal actions, are automatically prevented.

6. Building the structure of the Digital Management Balance (DMB). The DMB structure integrates the data of accounting registers and all forms of financial statements. It is important to note that the proposed approach does not cancel and does not change the rules of conducting official accounting, but forms in an automated way on the basis of embedded economic and mathematical algorithms a new report form structure developed using a fundamentally new methodology for cascade coding of transactions with disclosure of their economic and legal content. The DMB reflects detailed, reliable and integrated by the principle of connectedness information corresponding to the data of the UDP, the report on the implementation of the plan and the analysis of financial and economic activities. Unlike the existing form of the balance sheet, the created new structure of the DMB reflects the information multifunctionality on the accounting operations performed by each indicator code, taking into account the business transaction codes for accessible perception and understanding of the necessary information by managers who do not have deep knowledge of a complex accounting language.

7. Systematic comprehensive analysis of financial and economic activities. This approach provides for operational (with a daily or more short-term interval), the socalled "signal-regulated analysis" of production and sales of products; monthly analysis of all key calculated indicators; analysis of indicators of real savings or loss of financial resources; analysis of indicators on balance sheet accounts; formation of a daily report on the implementation of the plan for operational monitoring indicators. 
8. Comprehensive information connectivity. This approach allows you to "link" the regulatory, technological and economically justified costs - calculations - results of financial and economic activities for each type of product, order, contract separately and the organization. This approach establishes the interconnection not only of all indicators of the UDP, financial statements and the MIBM, but also integrates all the functions of managing economic activity into a single chain.

9. Coding of functional and structural indicators. This approach of multilevel cascade coding of functional-structural and organizational-legal aspects, taking into account the business management hierarchy, is intended for systematic and operational analysis of various areas of activity by industry, types of products (works, services), various orders, projects, objects and other indicators. Functional and structural classification of indicators is focused on solving such problems as rationing, balanced planning, control of the composition and structure of income, expenses and sources of funds of each subordinate responsibility center (division) and the organization as a whole; obtaining operational consolidated production and economic information comparable in structural units to organizations; forming of balanced operating and financial budgets with the necessary interconnection of indicators and the level of detail of planned information.

10. Treasury budget execution. According to this approach, personal accounts are opened on a single "treasury" account for subordinate structural units of the organization. The control of the treasury execution of budgets in the information system is carried out based on codes for the functional and structural purpose. Such centralization makes it possible to unite all financial resources in order to provide "internal" loans to departments, responsibility centers, subsidiaries in the case of creating negative cash gaps, to reduce the cost of servicing borrowed funds, and in the case creating positive cash gaps, to receive additional income from temporary placement of free cash in financial assets.

11. Formation of unified management assessment (UMA). Analysis of the proposed significant set of estimated indicators (the number of which is more than two hundred) makes it possible to examine in detail various aspects of financial and economic activity. However, it is not possible to assess the holistic real picture of economic activity management and determine the state of the organization's health and development prospects by the main vectors. To solve this problem, an economic-mathematical algorithm for forming a single assessment of the quality of business management has been developed, which, using the original mechanism, summarizes the entire set of analytical indicators of financial and economic activity. This methodological approach provides obtaining of complete and reliable information about the use of all production, financial, labor and other resources of the organization. UMA, as an information tool allows monthly, in an aggregated form, to identify the state and change in the property and financial position of the organization, diagnose the nature of the results of production and economic activity, establish the reasons for the dynamics of the financial condition and use a 
generalized assessment to make timely decisions to eliminate bottlenecks and prevent negative external impact and internal factors in the future.

The developed methodology for assessing the organization's management quality on the basis of the proposed mechanism for the formation of a cascaded data system is universal in nature and can be used for various subjects of economic entrepreneurial activity, regardless of its scale, industry and organizational and legal affiliation, the analyzed period, and the form of disclosure of analytical indicators. UMA is the most important tool for the internal audit of technical and economic performance indicators, a kind of digital virtual auditor of problem areas. Along with positive changes in key performance indicators, any organization may have unused opportunities - reserves, the identification and implementation of which in the future can provide a higher level of business efficiency, increase economic potential and strengthen the competitiveness of organizations. Management quality assessment is carried out by comparing data for the reporting period with comparable data for previous years and with budget indicators; actual data for certain periods of the reporting year; planned data in comparison with reporting indicators.

12. Operational regulation of the organization. The developed methodology provides a real opportunity, based on automatically generated operational reports on the performance of planned indicators, analysis and assessment of management quality, as well as information on the unsatisfactory work of specific departments, responsibility centers, divisions, to make operational decisions on the regulation of their activities, excluding possible subjectivity and biased assessments managerial workers.

\section{Conclusion}

The developed methodological approaches of the MIBM allow individuals making operational and strategic management decisions to justify them using a high-quality information base in formats adapted to the level and profile of the production and economic problems they solve. Considering the possibility of a significant reduction in the time period for providing the requested information to users, managerial employees can carry out their functions of operational regulation of the organization's activities, in many respects anticipating the occurrence of violations and negative contingencies. At the same time, justified and authorized adjustments of budget indicators will make it possible to adapt the business management system considering the changing external environment, economic conditions and, thereby, ensure realistic plans and the feasibility of their implementation.

\section{References:}

Ansoff, I. 1989. Strategic management. M.: Economics, 358 p.

Decree of the Government of the Russian Federation of April 15, 2014 No. 313 "On approval of the state program of the Russian Federation "Information Society" (2011-2020)".

Decree of the Government of the Russian Federation of 08.28.2017 No. 1030 "On the 
implementation management system of the program "Digital Economy of the Russian Federation"”.

DiPiazza Jr, S.A., Eccles, R.J. 2003. The Future of Corporate Reporting. How to restore public trust. M.: Alpina Publisher, $221 \mathrm{p}$.

Dunets, A., Latysheva, O., Bitter, N., Vakhrushev, I., Shichiyakh, R., Zhuruli, G. 2019a. The economic and infrastructural basis for the development of tourist space: The essence, structure and typology. Journal of Environmental Management and Tourism, 10(2), 319-327. doi:10.14505/jemt.v10.2(34).05

Dunets, A., Muhamedieva, A., Sycheva, I., Perepechkina, E., Vakhrushev, I., Kulchytskiy, A. 2019b. Spatial tourism planning: Using the model of functional and planning complexes. Journal of Environmental Management and Tourism, 10(4), 711-719. doi:10.14505/jemt.v10.4(36).01

Fedulova, I., Ivanova, V., Atyukova, O., Nosov, V. 2019. Inclusive education as a basis for sustainable development of society. Journal of Social Studies Education Research, $10(3), 118-135$.

Frolova, I., Voronkova, O., Islamutdinova, D., Gordeyeva, O., Fedulova, I., Zhminko, A. 2019. Ecologization of agroindustrial production: Organizational and economic transformations. Journal of Environmental Management and Tourism, 10(3), 622630. doi:10.14505/jemt.v10.3(35).16

Goryushkina, N.E., Vakhrushev, I.B., Akhmetova, M.K., Otto, O.V., Pesotskaya, E.V., Voinova, N.E. 2018. The world hotel market: Current state and development trends. International Journal of Mechanical Engineering and Technology, 9(12), 618-627.

Isaev, D.V. 2018. Corporate reporting: trends and prospects. Financial newspaper, 17(853), 14-15.

Ivanova, V., Poltarykhin, A., Szromnik, A., Anichkina, O. 2019. Economic policy for country's digitalization: A case study. Entrepreneurship and Sustainability Issues, 7(1), 649-661. doi:10.9770/jesi.2019.7.1(46).

Jafarpour, H., Moghadasi, J., Khormali, A., Petrakov, D.G., Ashena, R. 2019. Increasing the stimulation efficiency of heterogeneous carbonate reservoirs by developing a multibached acid system. Journal of Petroleum Science and Engineering, 172, 50-59. doi:10.1016/j.petrol.2018.09.034.

Kaplan, R.S., Norton, D. 2005. Balanced scorecard. From strategy to action. 2nd ed., rev. and add.: transl. from English. M.: CJSC "Olymp-Business", 320 p.

Kashirskaya, L., Voronkova, O., Sitnov, A., Shichiyakh, R., Kudinova, M., Sycheva, I. 2019. Rural development through the formation of zonal agro-ecological clusters. Journal of Environmental Management and Tourism, 10(3), 651-659. doi:10.14505/jemt.v10.3(35).19.

Korableva, O.N., Kalimullina, O.V., Mityakova, V.N. 2019. Designing a System for Integration of Macroeconomic and Statistical Data Based on Ontology. Advances in Intelligent Systems and Computing, 998, 157-165.

Khormali, A., Petrakov, D.G., Afshari, M.J. 2016. Experimental analysis of calcium carbonate scale formation and inhibition in waterflooding of carbonate reservoirs. Journal of Petroleum Science and Engineering, 147, 843-850. doi:10.1016/j.petrol.2016.09.048.

Kolupaev, A.A., Voronkova, O.Y., Vakhrushev, I.B., Adamenko, A.A., Solodkin, V.S., Alekhina, N.A. 2019. Corporate identity of lodging establishment as a factor of increasing tourism activity in the region. Paper presented at the Proceedings of the 33rd International Business Information Management Association Conference, IBIMA 2019: Education Excellence and Innovation Management through Vision 
2020, 7948-7956.

Order of the Government of the Russian Federation of July 28, 2017 No. 1632 "Digital Economy of the Russian Federation program".

Paptsov, A., Nechaev, V., Mikhailushkin, P. 2019. Towards to a single innovation space in the agrarian sector of the member states of the eurasian economic union: A case study. Entrepreneurship and Sustainability Issues, 7(1), 637-648. doi:10.9770/jesi.2019.7.1(45).

Pavlyshyn, L., Voronkova, O., Yakutina, M., Tesleva, E. 2019. Ethical problems concerning dialectic interaction of culture and civilization. Journal of Social Studies Education Research, 10(3), 236-248.

Radina, V.A. 2015. Creation of new methodological approaches on financial management. Accounting, Analysis, Audit, No. 3, 115-121.

Rupeika-Apoga, R., Saksonova, S. 2018. SMEs' Alternative Financing: The Case of Latvia. European Research Studies Journal, 21(3), 43-52. DOI: 10.35808/ersj/1042.

Rupeika-Apoga, R., Zaidi, H.S., Thalassinos, E.Y., Thalassinos, I.E. 2018. Bank Stability: The Case of Nordic and Non-Nordic Banks in Latvia. International Journal of Economics and Business Administration, 6(2), 39-55.

Saenko, N., Voronkova, O., Volk, M., Voroshilova, O. 2019. The social responsibility of a scientist: Philosophical aspect of contemporary discussions. Journal of Social Studies Education Research, 10(3), 332-345.

Solovjova, I., Rupeika-Apoga, R., Romanova, I. 2018. Competitiveness Enhancement of International Financial Centres. European Research Studies Journal, 21(1), 5-17. DOI: $10.35808 / \mathrm{ersj} / 925$.

Yakutin, Yu.V. 2016. The Requirement of the sixth technological order to digital management: the principle of connectedness of coded indicators of financial and economic activity of enterprises. Ekonomicheskaya Gazeta, No. 4, 59-82.

Voronkova, O., Yankovskaya, V., Kovaleva, I., Epishkin, I., Iusupova, I., Berdova, Y. 2019. Sustainable territorial development based on the effective use of resource potential. Entrepreneurship and Sustainability Issues, 7(1), 662-673. doi:10.9770/jesi.2019.7.1(47) 